SUPPORTING INFORMATION

\title{
Bifunctional ruthenium nanoparticle-SILP catalysts (RuNPs@SILP) for the hydrodeoxygenation of eucalyptol under batch and continuous flow conditions
}

Kylie L. Luska, ${ }^{a}$ Pedro Migowski, ${ }^{a}$ Sami El Sayed a and Walter Leitner ${ }^{* a, b}$

[a] Institut für Technische und Makromolekulare Chemie, RWTH Aaachen University, Worringerweg 1, 52074 Aachen, Germany

[b] Max-Planck-Institut für Kohlenforschung, 45470 Mülheim an der Ruhr, Germany

\section{$\underline{\text { TABLE OF CONTENTS }}$}

$\begin{array}{lc}\text { 1. Experimental } & \text { S3 }\end{array}$

$\begin{array}{lr}\text { 1.1. General } & S 3\end{array}$

$\begin{array}{ll}\text { 1.2. Analytics } & S 3\end{array}$

2. Synthesis of Supported Ionic Liquid Phases and Bifunctional Catalysts $\quad$ S4

2.1 Synthesis of Supported Ionic Liquid Phases $\quad S 4$

$\begin{array}{ll}2.1 .1 \text { SILP-1.00 } & \text { S4 }\end{array}$

$\begin{array}{lr}\text { 2.1.2 SILP-0.66 } & \text { S4 }\end{array}$

\begin{tabular}{lr}
2.1 .3 SILP-0.33 S4 \\
\hline
\end{tabular}

$\begin{array}{lr}\text { 2.1.4 SILP-0.00 } & \text { S4 }\end{array}$

2.2 Synthesis of Bifunctional Catalysts $\quad S 5$

2.2.1RuNPs@SILP $\quad$ S5

2.2.2RuNPs@IL $\quad$ S5

$\begin{array}{lr}\text { 3. Catalytic Data for the Deoxygenation of Eucalyptol } & \text { S6 }\end{array}$

$\begin{array}{ll}\text { 3.1. Batch Conditions } & S 6\end{array}$

3.2. Continuous Flow Conditions $\quad S 6$

$\begin{array}{lr}\text { 3.3. Kinetic Experiments } & S 7\end{array}$

$\begin{array}{lr}\text { 4. Electron Microscopy Data } & \text { S9 }\end{array}$

$\begin{array}{lr}4.1 \text { Preparation of Electron Microscopy Samples } & S 9\end{array}$

$\begin{array}{lr}4.2 \text { Electron Microscopic Images } & S 9\end{array}$

$\begin{array}{lr}\text { 5. References } & \mathbf{S 1 1}\end{array}$

Total Number of Pages: 11

Total Number of Figures: 6

Total Number of Schemes: 1

Total Number of Tables: 2 


\section{LIST OF FigURES, SCHEMES AND TABLES}

Scheme S1. Synthesis of supported ionic liquid phases (SILPS)

Table S1. Characterization of supported ionic liquid phases (SILPS)

Figure S1. Three-dimensional response surface for the conversion of eucalyptol under continuous flow conditions with respect to the reaction temperature and substrate flow and catalyzed by RuNPs@SILP-1.00

Table S2. Characterization of RuNPs@SILP-1.00 before and after catalysis under continuous flow conditions

Figure S2. Kinetic data for the elementary and the integrated/tandem reactions involved in the deoxygenation of eucalyptol: (a) eucalyptol dehydration using SILP-1.00; (b) diene and alkene hydrogenation using RuNPs@SILP-0.00 (determined by $\mathrm{H}_{2}$ consumption); (c) deoxygenation of eucalyptol using RuNPs@SILP-0.33; (d) deoxygenation of eucalyptol using RuNPs@SILP-0.66; (e) deoxygenation of eucalyptol using RuNPs@SILP-1.00; and (f) deoxygenation of eucalyptol using a physical mixture (RuNPs@SILP-0.00 + SILP-1.00)

Figure S3. Scanning transmission electron microscopic images of (a) RuNPs@SILP-0.00 (1.9 $\pm 0.3 \mathrm{~nm})$,

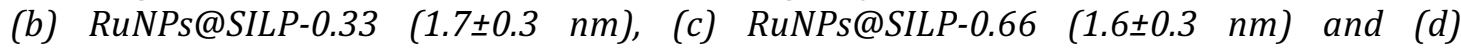

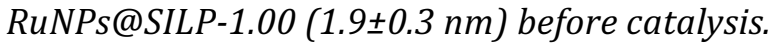

Figure S4. Scanning transmission electron microscopic histograms for (a) RuNPs@SILP-0.00, (b) RuNPs@SILP-0.33, (c)RuNPs@SILP-0.66 and (d) RuNPs@SILP-1.00 before catalysis.

Figure S5. Scanning transmission electron microscopic (a) image and (b) histogram for RuNPs@SILP$1.00(1.7 \pm 0.3 \mathrm{~nm})$ after the deoxygenation of eucalyptol under continuous flow conditions (substrate $=0.05 \mathrm{M}$ eucalyptol in heptane, $0.6 \mathrm{~mL} \cdot \mathrm{min}^{-1}$; pressure of $H_{2(g)}=80 \mathrm{bar}, 20$ $\mathrm{NmL} \cdot \mathrm{min}^{-1} ; t=5 \mathrm{~h} ; \mathrm{T}=130^{\circ} \mathrm{C}$ ).

Figure S6. Transmission electron microscopic images of Ru NPs stabilized in [1-butyl-3-(4-sulfobutyl)imidazolium]NTf 2 (a) before $(2.3 \pm 0.5 \mathrm{~nm})$ and (b) after catalysis $(3.0 \pm 0.6 \mathrm{~nm})$. 


\section{Experimental}

\section{Safety Warning}

High-pressure experiments with compressed $\mathrm{H}_{2(\mathrm{~g})}$ must be carried out only with appropriate equipment and under rigorous safety precautions.

\subsection{General}

The synthesis of supported ionic liquid phases (SILPs) and ruthenium nanoparticles immobilized on SILPs (RuNPs@SILP) were carried out under an inert atmosphere using standard Schlenk techniques. After synthesis, SILPs and RuNPs@SILPs were stored under an inert atmosphere prior to use. The catalysis substrates were stored under atmospheric conditions prior to use. Catalyst solutions and substrates were handled under air, but were flushed with $\mathrm{H}_{2(\mathrm{~g})}$ prior to catalysis. SILPs were synthesized using a modified literature procedure (vide infra). ${ }^{1}$ [1-butyl-3-(4sulfobutyl)imidazolium]NTf ${ }_{2}{ }^{2}$ RuNPs@SILP1 and RuNPs@IL ${ }^{2}$ were synthesized according to known literature methods. $\mathrm{SiO}_{2}$ (Merck Grade 10184, pore size 100 $\mathrm{A}, 63-200 \mu \mathrm{m}$ ) was dehydroxylated in vacuo at $500^{\circ} \mathrm{C}$ for at least $16 \mathrm{~h}$ before use. Toluene was prepared by distillation and drying over activated alumina using a purification system. Anhydrous EtOH (extra dry, absolute) was purchased from Acros Organics. All other chemicals and solvents were purchased from commercial sources and used without purification.

\subsection{Analytics}

High-pressure experiments under batch conditions were performed using in-house engineered 10 and $20 \mathrm{~mL}$ stainless steel finger autoclaves. Catalysis reactions were performed in glass inlets using a magnetic stirbar $(600 \mathrm{rpm})$ and an aluminum heating block. Continuous flow experiments were conducted using a Thales Nano H-Cube Pro ${ }^{\mathrm{T}}$ equipped with a H-Cube ${ }^{\circledR}$ Gas Module (for external $\mathrm{H}_{2(\mathrm{~g})}$ usage) and employing $70 \mathrm{~mm}$ CatCart ${ }^{\circledR}$ cartridges. Gas chromatography (GC) was performed on a Thermo Scientific Chromatograph Tace GC Ultra equipped with a CP-WAX-52CB column. Transmission electron microscopic (TEM) images were obtained on a Hitachi HF-2000 operating at $200 \mathrm{kV}$. Scanning transmission electron microscopic (STEM) images were collected on a Hitachi S-5500 operating at 30 $\mathrm{kV}$ and with a point resolution of $4 \AA$. Brunauer-Emmett-Teller (BET) measurements were performed on a Quantachrome Instruments Quadrasord SI automated Surface Area and Pore Size Analyzer and data analysis performed using QuadraWin 5-04. Inductively coupled plasma (ICP) was performed at Mikroanalytisches Laboratorium Kolbe (Mülheim an der Ruhr, Germany) using a Perkin Elmer AAnalyst 200 Atomic Absorption Spectrometer. 


\section{Synthesis of Supported Ionic Liquid Phases and Bifunctional Catalysts}

\subsection{Synthesis of Supported Ionic Liquid Phases}

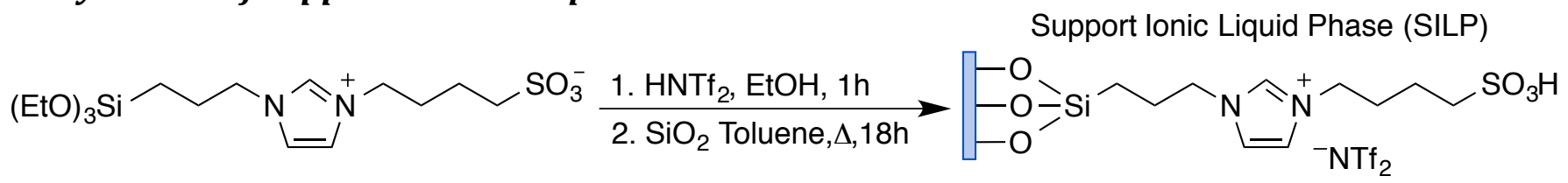

Scheme S1. Synthesis of supported ionic liquid phases (SILPs)

\subsubsection{SILP-1.00}

1-(4-sulfobutyl)-3-(3-triethoxysilylpropyl)imidazolium zwitterion (7.19 g, $17.6 \mathrm{mmol}$ ) and $\mathrm{HNTf}_{2}$ (4.95 g, $17.6 \mathrm{mmol}$ ) were dissolved in anhydrous EtOH (5 mL) and stirred at $\mathrm{rt}$ for $1 \mathrm{~h}$. The IL solution was added to a suspension of dehydroxylated $\mathrm{SiO}_{2}(20.0 \mathrm{~g}$ in $100 \mathrm{~mL}$ toluene) and the mixture was refluxed for $18 \mathrm{~h}$. Upon removal of the organic phase, the SILP was washed with anhydrous EtOH $(3 \mathrm{x}$ $40 \mathrm{~mL}$ ) and dried in vacuo at $50^{\circ} \mathrm{C}$ for $16 \mathrm{~h}$. The organic phases were combined and solvent removed to determine the residual quantity of IL not grafted onto $\mathrm{SiO}_{2}$ (Total IL Loading = Theoretical Loading Recovered Residual IL).

\subsubsection{SILP-0.66}

1-(4-sulfobutyl)-3-(3-triethoxysilylpropyl)imidazolium zwitterion (4.78 g, $11.7 \mathrm{mmol}$ ), [1-butyl-3-(3triethoxysilylpropyl)imidazolium]NTf 2 (3.58 g, $5.87 \mathrm{mmol})$ and $\mathrm{HNTf}_{2}(3.39 \mathrm{~g}, 11.7 \mathrm{mmol})$ were dissolved in anhydrous EtOH ( $5 \mathrm{~mL})$ and stirred at $\mathrm{rt}$ for $1 \mathrm{~h}$. The remainder of the reaction was performed as outline for SILP-1.00.

\subsubsection{SILP-0.33}

[1-(4-sulfobutyl)-3-(3-triethoxysilylpropyl)imidazolium] zwitterion $(2.40 \mathrm{~g}, 5.87 \mathrm{mmol})$, [1-butyl-3-(3triethoxysilylpropyl)imidazolium]NTf $2(7.13 \mathrm{~g}, 11.7 \mathrm{mmol})$ and $\mathrm{HNTf}_{2}(1.65 \mathrm{~g}, 5.87 \mathrm{mmol})$ were dissolved in anhydrous EtOH (5 mL) and stirred at $\mathrm{rt}$ for $1 \mathrm{~h}$. The remainder of the reaction was performed as outline for SILP-1.00.

\subsubsection{SILP-0.00}

[1-butyl-3-(3-triethoxysilylpropyl)imidazolium] $\mathrm{NTf}_{2}(10.73 \mathrm{~g}, 17.6 \mathrm{mmol})$ was dissolved in EtOH (5 $\mathrm{mL}$ ) and added to a suspension of dehydroxylated $\mathrm{SiO}_{2}(20 \mathrm{~g}$ in $100 \mathrm{~mL}$ toluene). The remainder of the reaction was performed as outline for SILP-1.00. 
Table S1. Characterization of supported ionic liquid phases

\begin{tabular}{|c|c|c|c|c|}
\hline Sample & Acid loading ${ }^{a}$ & 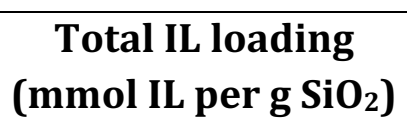 & $\begin{array}{c}\text { Surface area } \\
\left(\mathrm{m}^{2} \mathrm{~g}^{-1}\right)\end{array}$ & $\begin{array}{c}\text { Pore Radius } \\
\text { (Å) }\end{array}$ \\
\hline $\mathrm{SiO}_{2}$ & - & - & 247 & 45.2 \\
\hline SILP-0.00 & - & 0.53 & 259 & 36.2 \\
\hline SILP-0.33 & 0.33 & 0.66 & 189 & 40.7 \\
\hline SILP-0.66 & 0.66 & 0.68 & 182 & 41.3 \\
\hline SILP-1.00 & 1.00 & 0.68 & 169 & 42.1 \\
\hline RuNPs@SILP-1.00 & 1.00 & 0.68 & 170 & 42.8 \\
\hline
\end{tabular}

${ }^{a}$ Acid loading = [1-(4-sulfobutyl)-3-(3-triethoxysilylpropyl)imidazolium]NTf $2 /[1-(4-$ sulfobutyl)-3-(3triethoxysilylpropyl)imidazolium] $\mathrm{NTf}_{2}+$ [1-butyl-3-(3-triethoxysilylpropyl)imidazolium] $\mathrm{NTf}_{2 .}{ }^{b}$ Total IL loading $=$ theoretical IL loading - recovered residual IL (for theoretical IL loading $=0.88 \mathrm{mmol}$ IL per $\mathrm{g} \mathrm{SiO}_{2}$ ).

\subsection{Synthesis of Bifunctional Catalysts}

\subsubsection{RuNPs@SILP1}

[Ru(2-methylallyl $)_{2}$ (cod) $](40.8 \mathrm{mg}, 0.128 \mathrm{mmol})$ was dissolved in DCM $(10 \mathrm{~mL})$ and added to a suspension of SILP (4.0 g in $30 \mathrm{~mL}$ of DCM), upon which the SILP changed from a white to a bright yellow colour. The reaction mixture was stirred at $\mathrm{rt}$ for $1 \mathrm{~h}$. After solvent removal and in vacuo drying of the impregnated SILP, the powder was divided into two glass inserts, loaded into separate $20 \mathrm{~mL}$ high-pressure autoclaves and subjected to an atmosphere of $\mathrm{H}_{2(\mathrm{~g})}(120 \mathrm{bar})$ at $100^{\circ} \mathrm{C}$ for $16 \mathrm{~h}$. Under this reducing environment, the impregnated SILP transformed from a bright yellow to a dark black colour indicating the formation of Ru NPs.

\subsubsection{RuNPs@IL ${ }^{2}$}

[Ru(2-methylallyl) $\left.)_{2}(\mathrm{cod})\right]$ (1.3 mg, $\left.0.0024 \mathrm{mmol}\right)$ and [1-butyl-3-(4-sulfobutyl)imidazolium] $\mathrm{NTf}_{2}$ (27.6 $\mathrm{mg}, 0.051 \mathrm{mmol}$ ) were combined in a glass insert. The reaction mixture was loaded into a $10 \mathrm{~mL}$ highpressure autoclave and stirred under an atmosphere of $\mathrm{H}_{2(\mathrm{~g})}(60 \mathrm{bar})$ at $60^{\circ} \mathrm{C}$ for $2 \mathrm{~h}$. Under this reducing environment, the IL transformed from a colourless to a dark black colour indicating the formation of Ru NPs. 


\section{Catalytic Data for the Deoxygenation of Eucalyptol}

\subsection{Batch Conditions}

In a typical experiment, RuNPs@SILP (75 mg, 0.0024 mmol Ru) and eucalyptol (2.4 mmol, 1000 eq.) were combined in a glass insert and placed in a high-pressure autoclave. After purging the autoclave with $\mathrm{H}_{2(\mathrm{~g})}$, the reaction mixture was stirred at $150^{\circ} \mathrm{C}$ for $4 \mathrm{~h}$ in an aluminum heating block under 120 bar $\mathrm{H}_{2(\mathrm{~g})}$ (pressurized to 100 bar $\mathrm{H}_{2(\mathrm{~g})}$ at $\mathrm{rt}$ ). Once the reaction was finished, the reactor was cooled in an ice bath, carefully vented and the reaction mixture was analyzed via GC using hexadecane as an internal standard.

\subsection{Continuous Flow Conditions}

A 70 mm CatCart ${ }^{\circledR}$ was filled with RuNPs@SILP-1.00 (547 mg, $0.0175 \mathrm{mmol} \mathrm{Ru}$ ) and placed into the HCube Pro $^{\mathrm{TM}}$. Prior to catalysis, the catalyst was heated at $100^{\circ} \mathrm{C}$ under a flow of heptane $\left(0.3 \mathrm{~mL} \mathrm{~min}^{-1}\right)$ and $\mathrm{H}_{2(\mathrm{~g})}\left(80 \mathrm{bar}, 60 \mathrm{NmL} \mathrm{min}^{-1}\right.$ ) for 60 mins. The substrate solution (0.05 M eucalyptol in heptane) was introduced into the system with a flow of $\mathrm{H}_{2(\mathrm{~g})}(80 \mathrm{bar})$ and the reaction parameters (temperature $=113-147^{\circ} \mathrm{C}$, substrate flow $=0.3-0.9 \mathrm{~mL} \mathrm{~min}^{-1}, \mathrm{H}_{2}$ flow $=3-37 \mathrm{NmL} \mathrm{min}{ }^{-1}$ ) were varied. The system was allowed to equilibrate under the desired reaction conditions for 20 mins before $\sim 6 \mathrm{~mL}$ of reaction solution was collected. The reaction mixture was analyzed via GC using hexadecane as an internal standard.

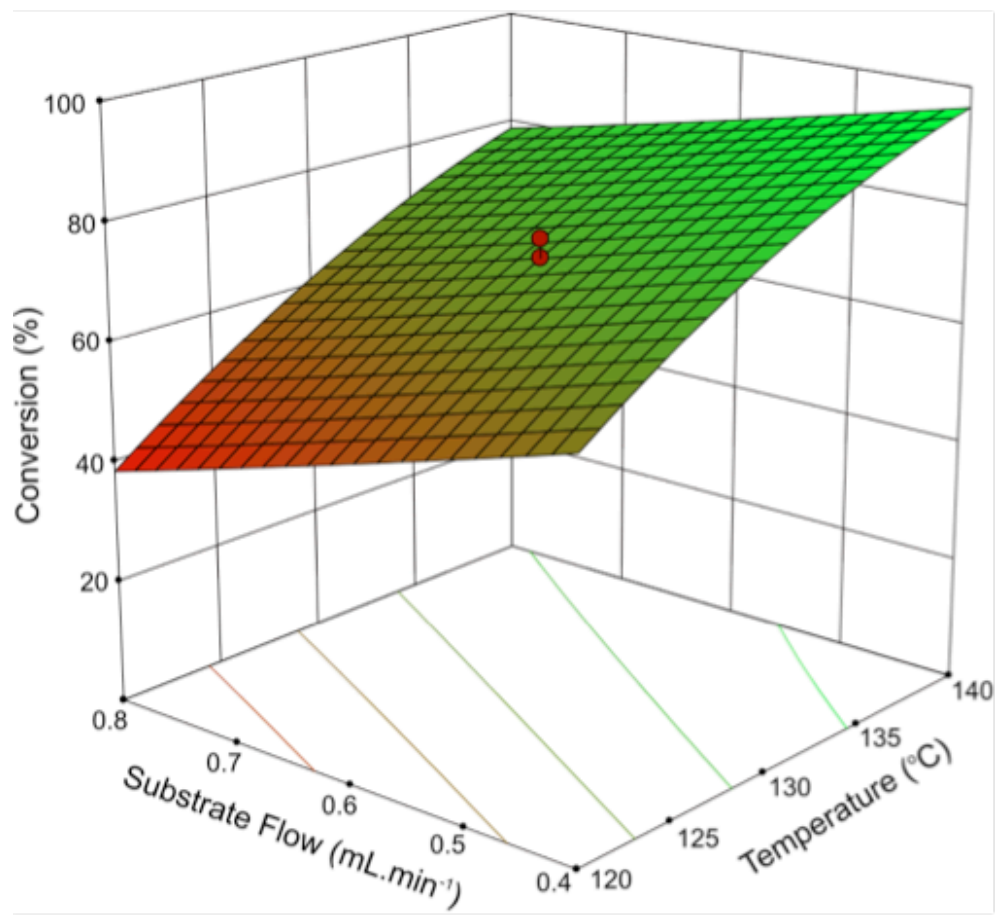

Figure S1. Three-dimensional response surface for the conversion of eucalyptol under continuous flow conditions with respect to the reaction temperature and substrate flow and catalyzed by RuNPs@SILP-1.00 
Table S2. Characterization of RuNPs@SILP-1.00 before and after catalysis under continuous flow conditions

\begin{tabular}{|c|c|c|c|c|c|}
\hline \multirow{2}{*}{ Sample } & \multirow{2}{*}{$\begin{array}{c}\text { Surface area } \\
\left(\mathrm{m}^{2} \cdot \mathrm{g}^{-1}\right)\end{array}$} & \multirow{2}{*}{$\begin{array}{c}\text { Pore radius } \\
\text { (Å) }\end{array}$} & \multicolumn{3}{|c|}{$\mathrm{ICP}(\mathrm{wt} \%)^{a}$} \\
\hline & & & $\mathbf{R u}$ & $\mathbf{N}$ & $\mathbf{S}$ \\
\hline Before catalysis & 170 & 42.8 & 0.23 & 1.86 & 4.26 \\
\hline After condition flow catalysis ${ }^{b}$ & 181 & 41.2 & 0.22 & 2.16 & 5.11 \\
\hline
\end{tabular}

${ }^{a}$ ICP experimental error $= \pm 0.01 \% \cdot{ }^{b}$ Reaction conditions: RuNPs@SILP-1.00 $(547 \mathrm{mg}, 0.0175 \mathrm{mmol}$ $\mathrm{Ru})$, substrate $\left(0.05 \mathrm{M}\right.$ in heptane, $\left.0.6 \mathrm{~mL} \cdot \mathrm{min}^{-1}\right), \mathrm{H}_{2}\left(80 \mathrm{bar}, 20 \mathrm{NmL} \cdot \mathrm{min}^{-1}\right), t=300 \mathrm{~min}, \mathrm{~T}=130^{\circ} \mathrm{C}$.

\subsection{Kinetic Experiments}

In a typical experiment, RuNPs@SILP (225 mg, $0.0072 \mathrm{mmol} \mathrm{Ru}$ ) and eucalyptol (7.2 mmol, 1000 eq.) were combined in a glass insert and placed in a $20 \mathrm{~mL}$ high-pressure autoclave. After purging the

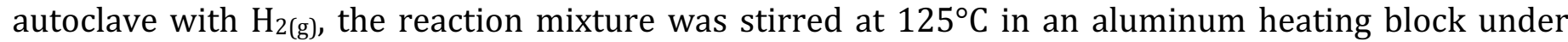

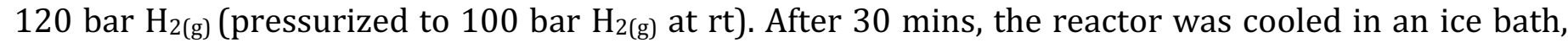
carefully vented and a small sample of the reaction mixture $(20 \mathrm{mg}$ ) was removed for GC analysis using hexadecane as an internal standard. The autoclave was repressurized with $\mathrm{H}_{2(\mathrm{~g})}$ and placed back onto heat at $125^{\circ} \mathrm{C}$. The reaction was monitored every 30 mins.

For the deoxygention of eucalyptol catalyzed by a physical mixture, RuNPs@SILP-0.00 (225 mg, 0.0072 $\mathrm{mmol} \mathrm{Ru}$ ) and SILP-1.00 (225 mg) was used in place of the bifunctional catalyst.

For diene and alkene hydrogenation, RuNPs@SILP-0.00 (225 mg, $0.0072 \mathrm{mmol} \mathrm{Ru}$ ) and terpinolene (7.2 mmol, 1000 eq.) were combined in a glass insert and placed in a $20 \mathrm{~mL}$ high-pressure autoclave.

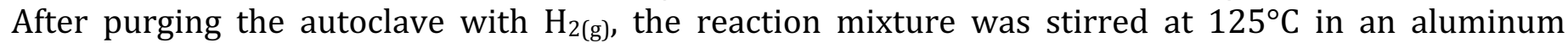
heating block under 120 bar $\mathrm{H}_{2(\mathrm{~g})}$ (pressurized to 100 bar $\mathrm{H}_{2(\mathrm{~g})}$ at $\mathrm{rt}$ ). The diene and alkene hydrogenation rates were determined by monitoring the consumption of $\mathrm{H}_{2(\mathrm{~g})}$ over the course of the reaction. Using the ideal gas law, the diene and alkene consumption rate were determined (for $\mathrm{V}_{\text {headspace }}=14.81 \mathrm{~mL}, \mathrm{~V}_{\text {solution }}=1.19 \mathrm{~mL}, \mathrm{~T}=125^{\circ} \mathrm{C}, \Delta \mathrm{n}_{\text {hydrogen }}=\Delta \mathrm{n}_{\text {dienes }}$ or $\Delta \mathrm{n}_{\text {hydrogen }}=\Delta \mathrm{n}_{\text {alkenes }}$ ). 
(a)

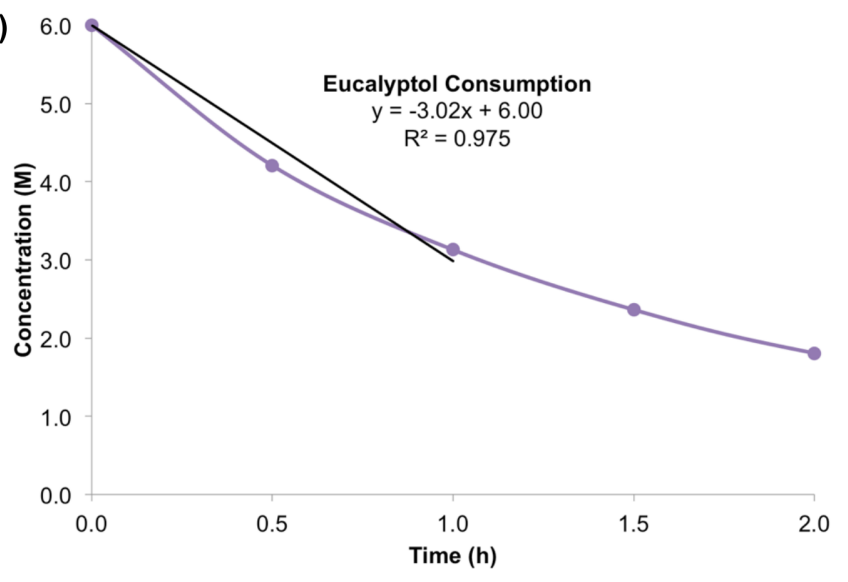

(c)

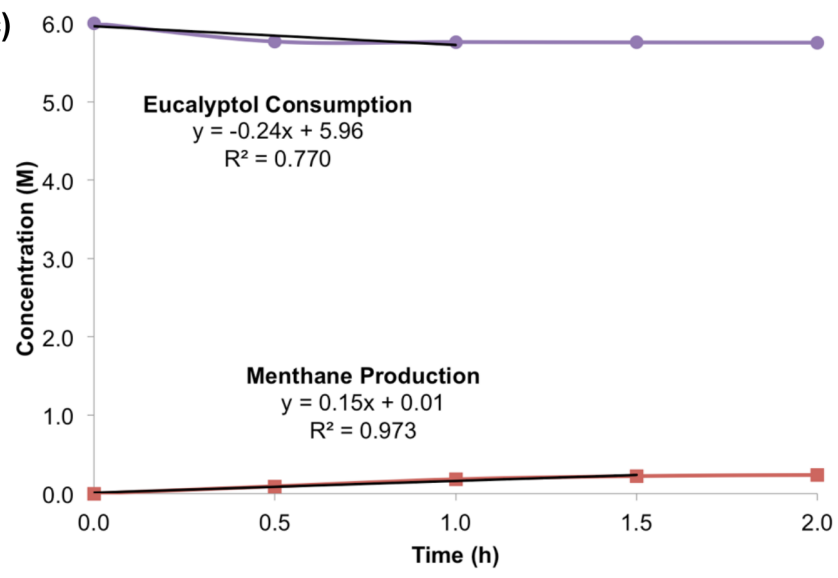

(e)

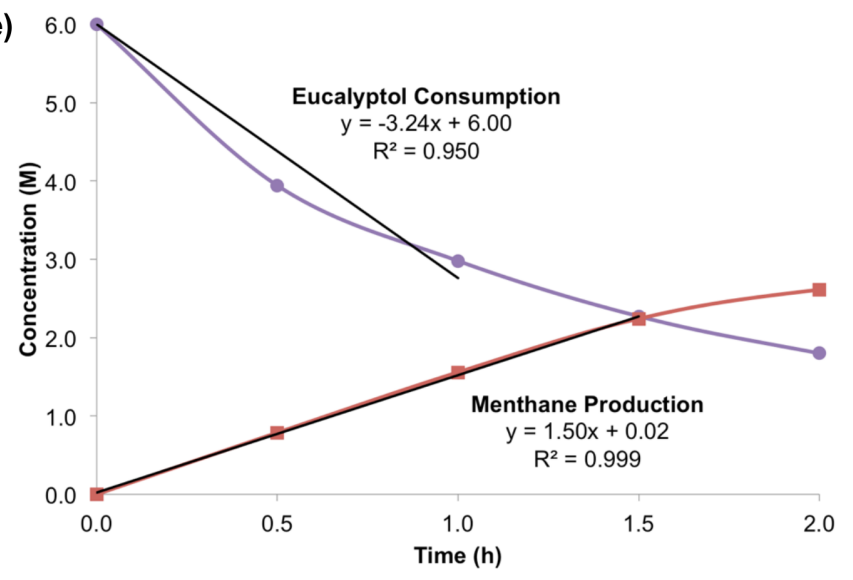

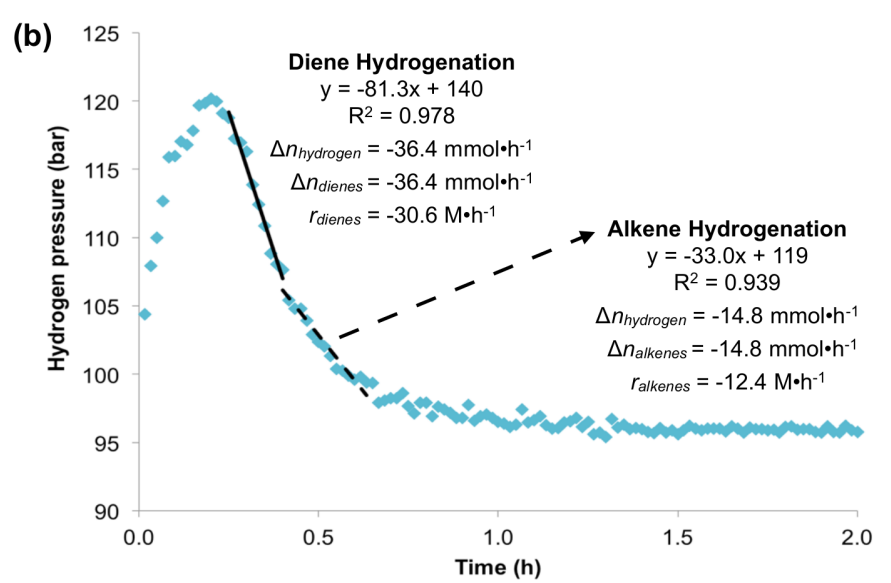

(d)

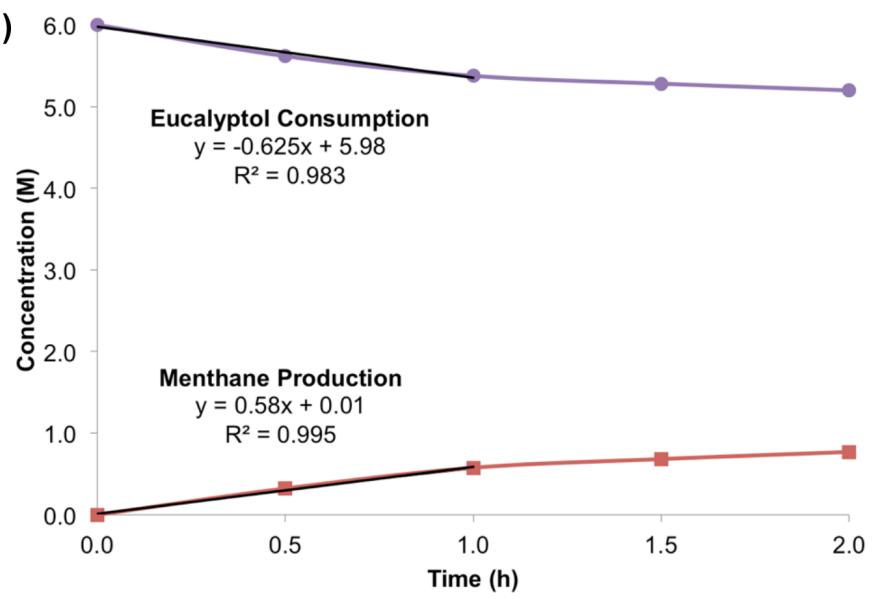

(f)

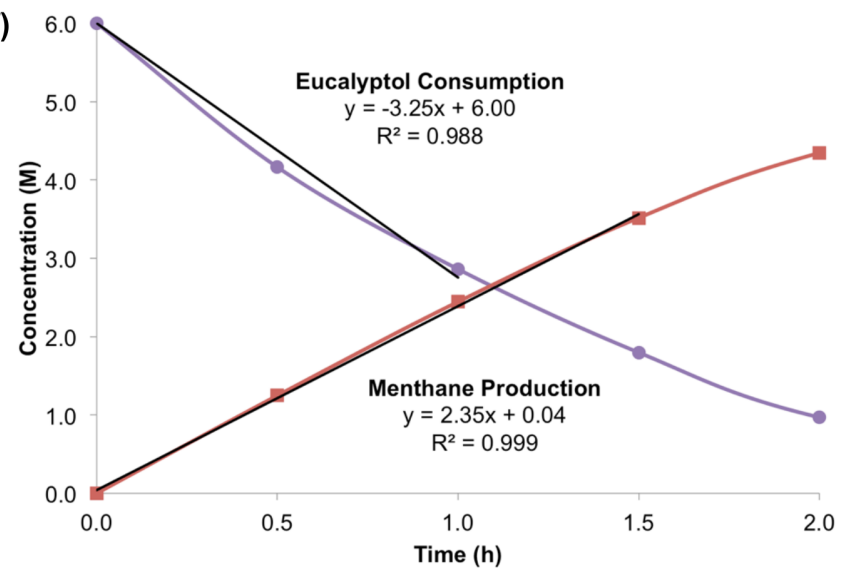

Figure S2. Kinetic data for the elementary and the integrated/tandem reactions involved in the deoxygenation of eucalyptol: (a) eucalyptol dehydration using SILP-1.00; (b) diene and alkene hydrogenation using RuNPs@SILP-0.00 (determined by $\mathrm{H}_{2}$ consumption); (c) deoxygenation of eucalyptol using RuNPs@SILP-0.33; (d) deoxygenation of eucalyptol using RuNPs@SILP-0.66; (e) deoxygenation of eucalyptol using RuNPs@SILP-1.00; and (f) deoxygenation of eucalyptol using a physical mixture (RuNPs@SILP-0.00 + SILP-1.00) 


\section{Electron Microscopy Data}

\subsection{Preparation of Electron Microscopy Samples}

Samples were prepared for TEM by ultrasound dispersion of RuNPs@IL in acetone, deposition of a drop of the suspension onto a carbon-coated copper grid (400 mesh) and drying in vacuo prior to analysis. TEM images were obtained on a Hitachi HF-2000 operating at an accelerating voltage of 200 $\mathrm{kV}$. The NP size and distribution was determined from the measurement of $>50$ spherical particles chosen in arbitrary areas of enlarged micrographs.

Preparation of samples for STEM involved embedding the RuNPs@SILPs into Spurr's resin, in which $28 \mathrm{~nm}$ thick sections were transferred onto a Lacey carbon-coated copper grid (400 mesh). STEM images were collected on a Hitachi S-5500 operating at an accelerating voltage of $30 \mathrm{kV}$. The NP size and distribution was determined from the measurement of $>100$ spherical particles chosen in arbitrary areas of enlarged micrographs.

\subsection{Electron Microscopic Images}
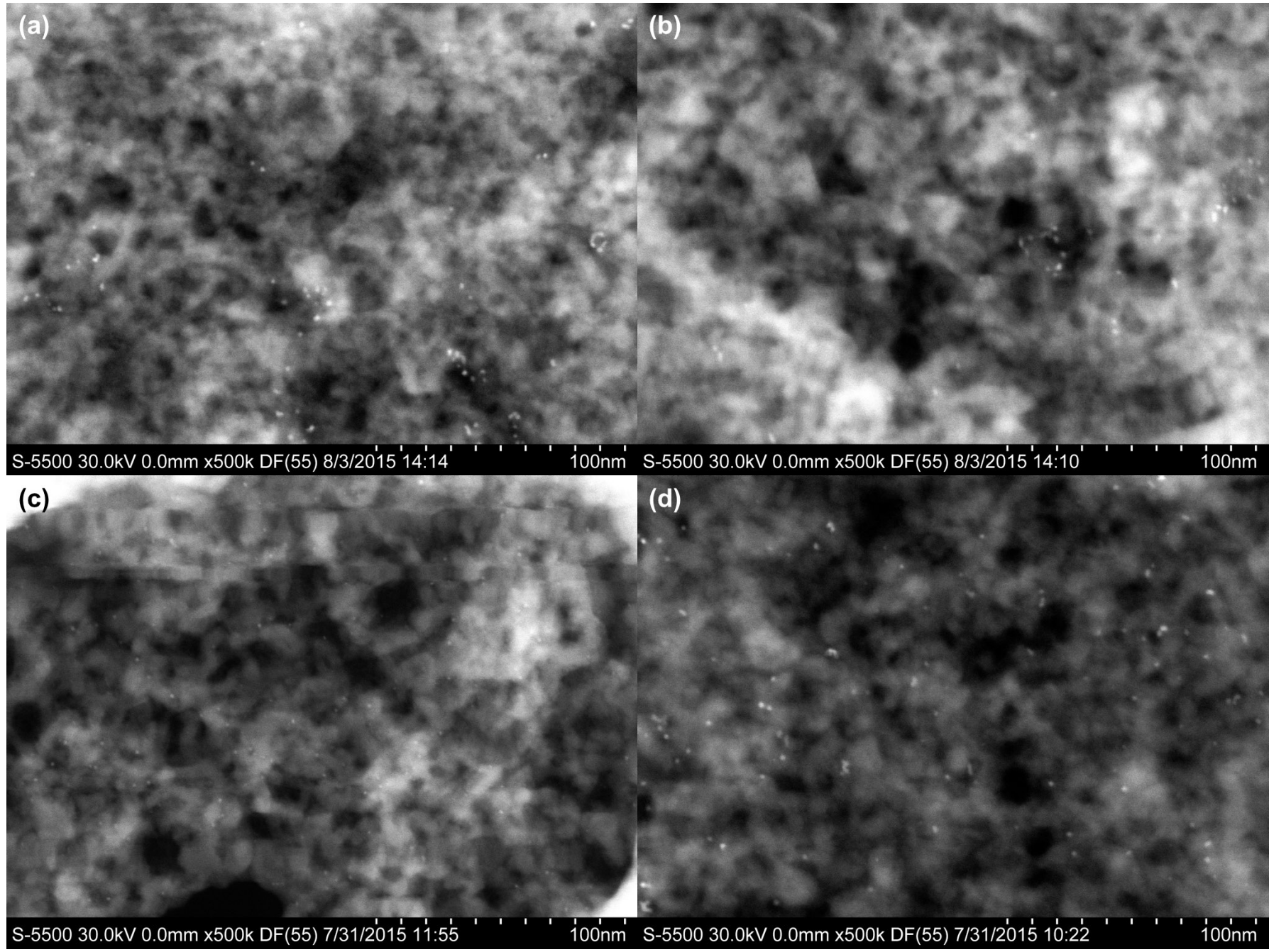

Figure S3. Scanning transmission electron microscopic images of (a) RuNPs@SILP-0.00 (1.9 $\pm 0.3 \mathrm{~nm})$,

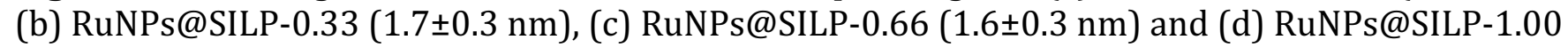
$(1.9 \pm 0.3 \mathrm{~nm})$ before catalysis. 
(a) 70

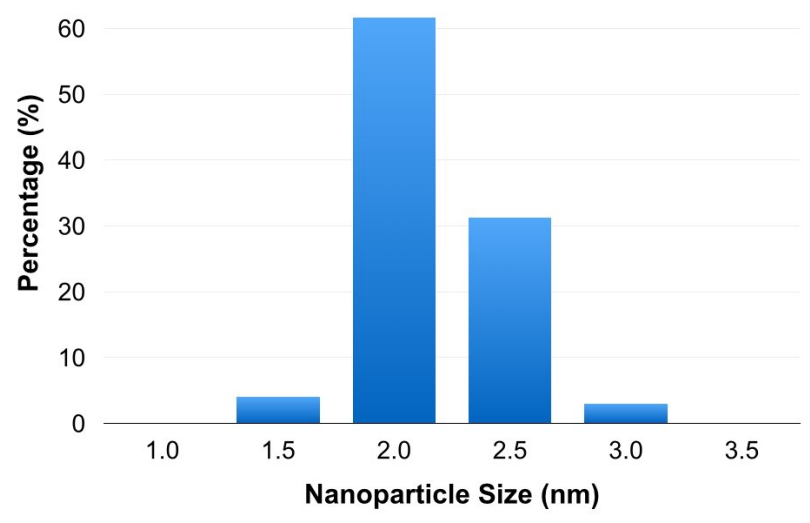

(c) 70

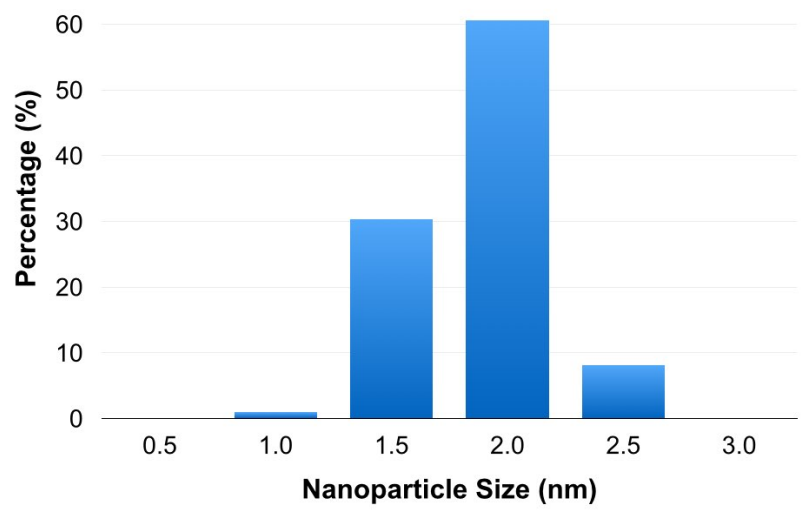

(b) 70

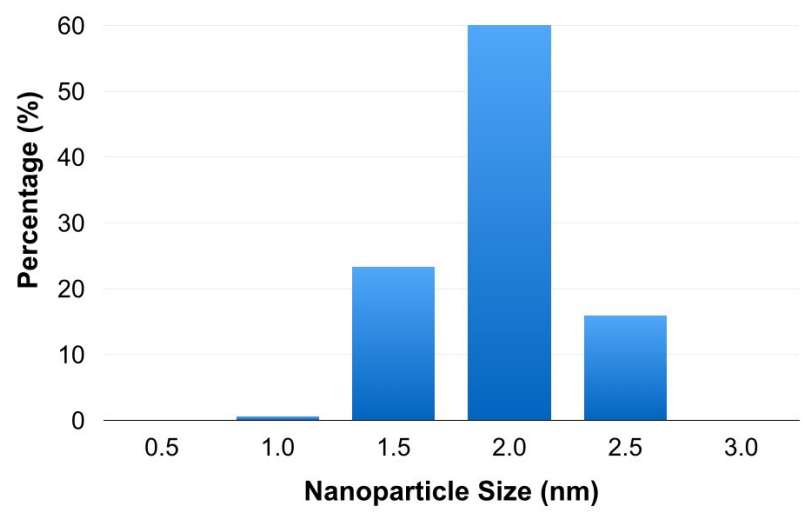

(d) 70

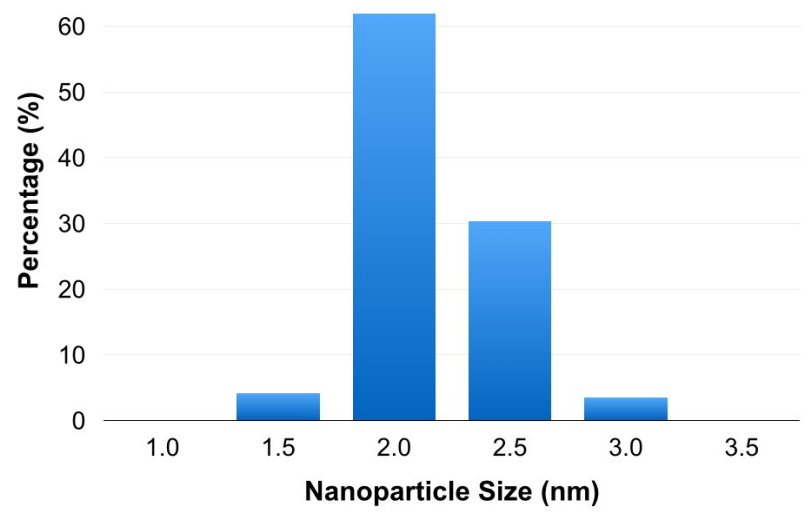

Figure S4. Scanning transmission electron microscopic histograms for (a) RuNPs@SILP-0.00, (b) RuNPs@SILP-0.33, (c) RuNPs@SILP-0.66 and (d) RuNPs@SILP-1.00 before catalysis.
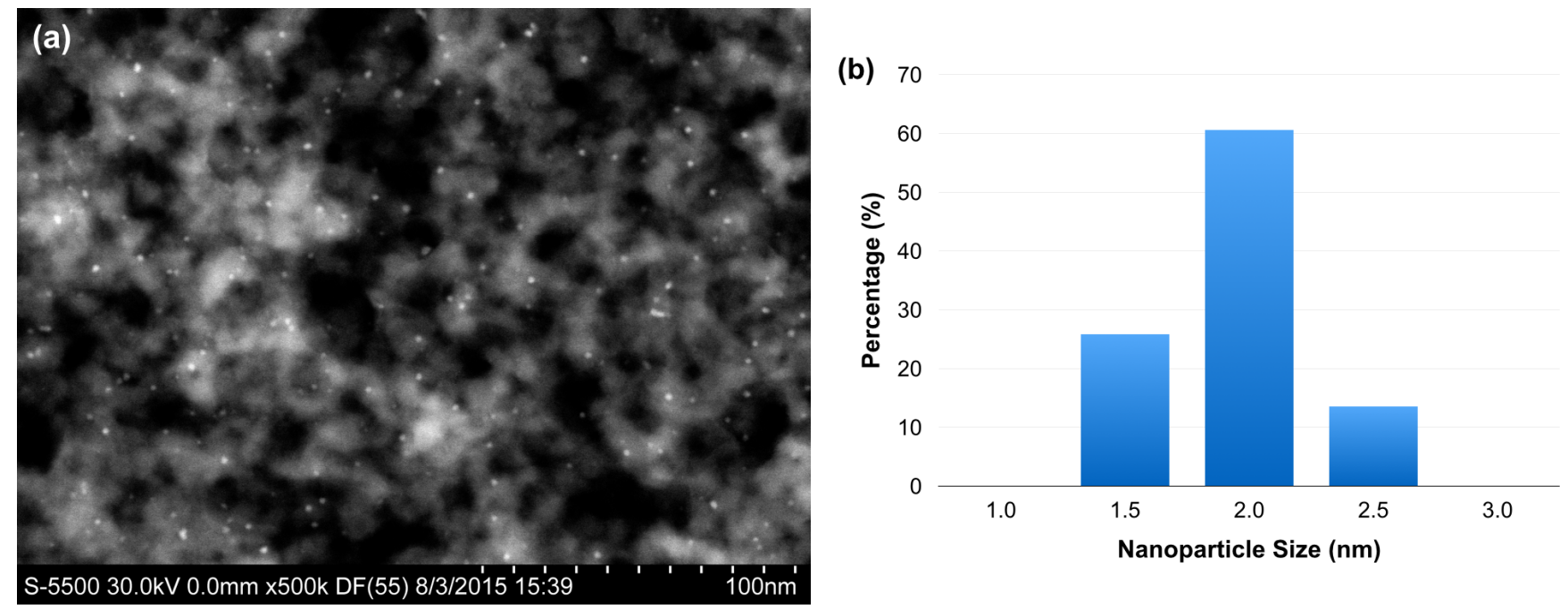

Figure S5. Scanning transmission electron microscopic (a) image and (b) histogram for RuNPs@SILP$1.00(1.7 \pm 0.3 \mathrm{~nm})$ after the deoxygenation of eucalyptol under continuous flow conditions (substrate = $0.05 \mathrm{M}$ eucalyptol in heptane, $0.6 \mathrm{~mL} \cdot \mathrm{min}^{-1}$; pressure of $\mathrm{H}_{2(\mathrm{~g})}=80 \mathrm{bar}, 20 \mathrm{NmL} \cdot \mathrm{min}^{-1} ; t=5 \mathrm{~h}$; $\mathrm{T}=$ $\left.130^{\circ} \mathrm{C}\right)$. 


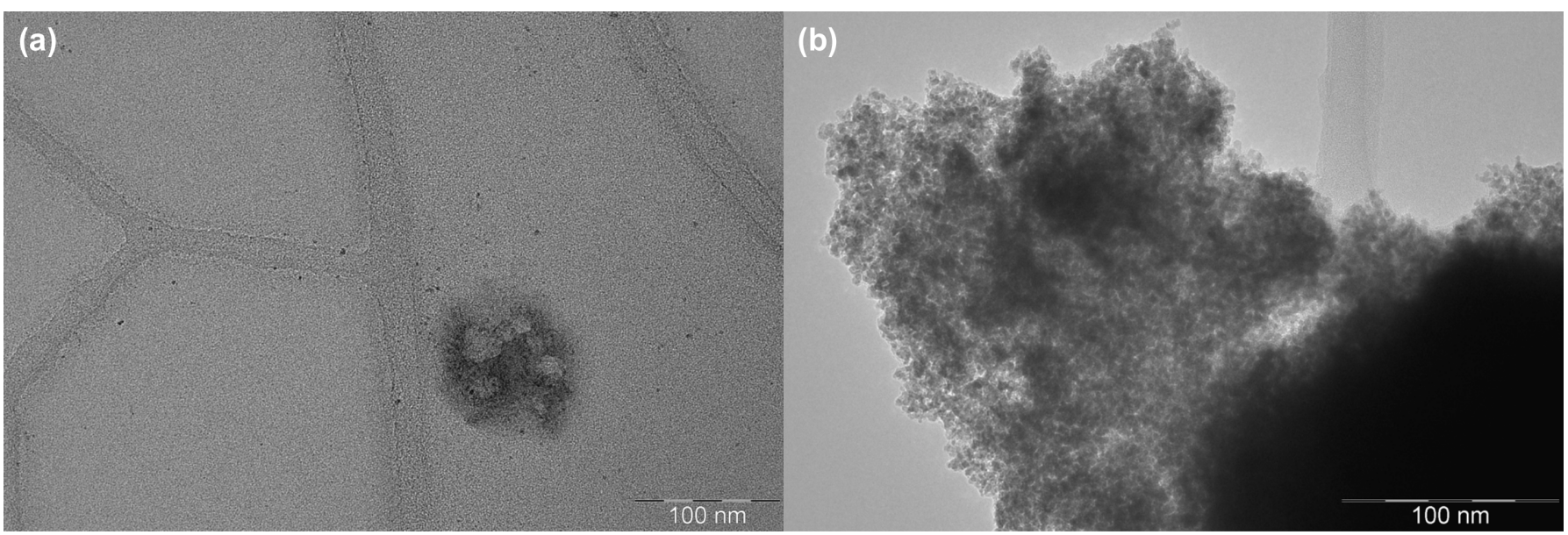

Figure S6. Transmission electron microscopic images of Ru NPs stabilized in [1-butyl-3-(4-sulfobutyl)imidazolium]NTf 2 (a) before $(2.3 \pm 0.5 \mathrm{~nm})$ and (b) after catalysis $(3.0 \pm 0.6 \mathrm{~nm})$.

\section{References}

1. Luska, K. L.; Julis, J.; Stavitski, E.; Zakharov, D. N.; Adams, A.; Leitner, W., Bifunctional nanoparticleSILP catalysts (NPs@SILP) for the selective deoxygenation of biomass substrates. Chem. Sci. 2014, 5, 4895-4905.

2. Julis, J.; Leitner, W., Synthesis of 1-Octanol and 1,1-Dioctyl Ether from Biomass-Derived Platform Chemicals. Angew. Chem. Int. Ed. 2012, 51, 8615-8619. 